\title{
EI otro en la mirada etnográfica. Guatemala (1920-1950)
}

\author{
Patricia Alvarenga
}

\author{
Escuela de Historia, Universidad Nacional (UNA), Costa Rica \\ patriciaalvarengavenutolo@gmail.com
}

\begin{abstract}
Resumen: Este artículo analiza diferentes representaciones de comunidades indígenas guatemaltecas durante la primera mitad del siglo XX. De igual forma, explora las perspectivas desde las cuales etnógrafos y antropólogos alemanes y estadounidenses explicaron las características culturas de estos pueblos. Esta investigación concluye con la figura de Antonio Goubaud Carrera, antropólogo guatemalteco vinculado con la antropología estadounidense y figura clave del proyecto de la Revolución Guatemalteca de 1944, la cual se proponía la integración del mundo indígena a la ciudadanía. El trabajo se fundamenta en el análisis de los textos escritos por nuestros sujetos de estudio y pretende ofrecer una visión crítica a las apreciaciones culturales que, en busca de la objetividad, fundamentan sus valoraciones de las otredades en posiciones de poder que generan distancias insalvables entre el observador y el observado.

Palabras clave: Antropología, etnografía, Guatemala, colonialidad, indígenas.
\end{abstract}

The other in the etnographic view. Guatemala (1920-1950)

Abstract: This article analizes different representations of Indian communities in the Altiplano Guatemalteco during the first half of the twentieth century. It explores the prospectives that German and Northamerican antrophologists utilized for explaining the cultural characteristics of these populations. These pages also includes the study of an antropologist from Guatemala: Antonio Goubaud Carrera, who was linked both to the northamerican antrophology and the Guatemalan Revolution from 1944, which proposed the Indian integration to the citizenship. This study is based on the analize of texts written by our subjets of study and it is looking for offer a critical prospectives of their visions, founded on positions of power which generate enormous distances among who observe and who is observed.

Keywords: Anthropology, ethnography, Guatemala, colonialism, indians.

Cuadernos de Antropología 2014, 24(2), 3-24

Recibido: 03-04-2014 / Aceptado: 01-11-2014

Revista del Laboratorio de Etnología María Eugenia Bozzoli Vargas

Escuela de Antropología, Universidad de Costa Rica

http://revistas.ucr.ac.cr/index.php/antropologia

ISSN 2215-356X

cC) (i) (-) Cuadernos de Antropología está bajo una licencia Creative Commons EY NC SA Attribution-NonCommercial-ShareAlike 3.0

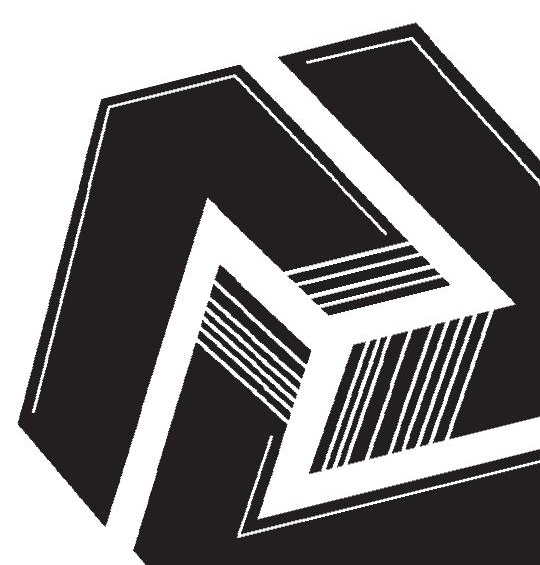




\section{Introducción}

Este artículo trata sobre la mirada etnográfica que construye a las diversas culturas indígenas del Altiplano Guatemalteco como otredad. Se circunscribe a un período en el que prevalece la hegemonía de investigadores extranjeros del mundo nórdico y se centra en el análisis de textos de etnógrafos alemanes y antropólogos estadounidenses. Una excepción en este estudio la constituye Antonio Goubaud Carrera, considerado el primer antropólogo profesional guatemalteco, quien estuvo estrechamente vinculado con la antropología estadounidense ${ }^{1}$. Si bien los alemanes estudiosos de la etnografía prevalecieron en Guatemala hasta la década de 1930, antropólogos profesionales estadounidenses empezaron a dominar el campo para entonces. La palabra "etnografía" fue sustituida por "antropología", cambio que estuvo vinculado con la construcción de los estudios de la diversidad cultural como una disciplina de las ciencias sociales. Este artículo contempla investigadores del período cuyos textos se localizan en Guatemala y otras bibliotecas de Centroamérica. En las siguientes páginas no se pretende realizar un estudio comprensivo de toda la producción etnográfica del período. Se incluyen dos etnográficos alemanes: Franz Termer y Leonhard Schultze-Jena. Asimismo, Sol Tax, Robert Redfield y el economista Sanford Mosk, constituyen ejemplos representativos de una red de intelectuales estadounidenses que establecen su hegemonía en los estudios sobre las culturas indígenas en las décadas de 1930 y 1940. De igual forma, se explora el trabajo de Antonio Goubaud, intelectual articulador del proyecto nacional que prevaleció durante la Revolución Guatemalteca entre 1944 y 1954 con el fin de visibilizar sus diálogos con las tradiciones etnográficas y antropológicas provenientes de Estados Unidos y Alemania ${ }^{2}$.

Este artículo no versa sobre las técnicas etnográficas, sino más bien refiere a la perspectiva desde la cual este disímil grupo de etnógrafos y antropólogos describen sus objetos-sujetos de estudio y cómo esta visión del otro permea su quehacer investigativo. Clifford Geertz (1988) se manifiesta en contra de la supuesta "inocencia literaria" del antropólogo como autor. En la escritura etnográfica ha prevalecido un "borramiento" del autor como sujeto interactuante. Este, como narrador objetivo de una realidad transparente, resulta, según este autor, igual de tramposo en antropología como lo sería en el análisis y la crítica artística. La "ventriloquía etnográfica", según Geertz (1988), refiere a que, inevitablemente, "toda descripción etnográfica es interesadamente casera, es siempre descripción del descriptor y no del descrito". Ello no expresa necesariamente una "condición defectuosa" del campo de estudio. Al contrario, cuando se toma conciencia de esta particularidad, el discurso etnográfico puede ser altamente productivo y ofrecer no solo nuevas dimensiones para mirar la otredad, sino también para mirarse a sí mismo. Este

\footnotetext{
1 Aunque recurrentemente se alude a Goubaud como el iniciador de este campo de estudios en Guatemala, él mismo señala ya en 1936 otros estudiosos guatemaltecos de la cultura indígena como José Antonio Villacorta, Eduardo Díaz, Jorge Luis Arriola y David Vela. En la década de 1940, Juan de Dios Rosales y Agustín Pop participan en investigaciones auspiciadas por la institución Carnegie y dirigidas por los estadounidenses Robert Redfield y Sol Tax (Goubaud, 1946).

2 Robert Redfield coordinó el programa "Middle American Cultural Anthropology". Con los auspicios del Instituto Carnegie, Redfield logró apoyar entre 1933 y 1945, diversos estudios de caso en la Península de Yucatán y las tierras altas de Guatemala (Bolaños, 1999).
} 
escritor, en la narrativa de Ruth Benedict, encuentra ricas potencialidades reflexivas gracias al artilugio que la lleva a transformar esa búsqueda de sí en otras realidades en un instrumento crítico de la propia cultura. No obstante, ha prevalecido en la modernidad y en particular en el trabajo etnográfico, una confusión entre la representación del sujeto y la pretensión de observarlo y captarlo tal cual es. Esta confusión no es inocente. El desarrollo de la etnografía y de la misma antropología ha estado vinculada con la colonialidad y, específicamente, con las instituciones en las que esta se ha reproducido, tales como museos, fundaciones y universidades (Spurr, 1993).

\section{La etnografía alemana a inicios del siglo $\mathrm{XX}$}

La monumentalidad de los restos arqueológicos, así como la presencia abrumadora de diversas culturas indígenas en el mundo social guatemalteco, constituyó fuente de atracción de investigadores europeos y más tardíamente estadounidenses. La excepcional influencia alemana en las investigaciones arqueológicas y etnográficas de Guatemala se corresponde con su incidencia en el terreno de las inversiones económicas (Wagner, 1996). Los investigadores alemanes, como los típicos intelectuales de los países hegemónicos que visitaron estos territorios, se desempeñaron en diversos campos del conocimiento; crearon sus propios recursos, métodos y perspectivas para aproximarse a las comunidades de su interés al valerse de sus conocimientos académicos relativos a las ciencias naturales. Por lo general, el interés en el estudio de la naturaleza derivó y se complementó con el estudio de la arqueología y de los indígenas contemporáneos (Sapper, 1930).

Sostiene Andrew Zimmerman (2001) que aún en las primeras décadas del siglo XX, los estudios etnográficos realizados por alemanes no se interesaron por crear una metodología para desarrollar el trabajo de campo. A partir de la contraposición cultura/naturaleza, figuras claves en el mundo intelectual berlinés, como Adolf Bastian y Rudolf Virchow, promovieron la recolección de objetos representativos de la diversidad cultural existente en el mundo, para estudiarlos y mostrarlos en monumentales museos. De acuerdo con Zimmerman (2001), estos objetos, provenientes del estático mundo de la naturaleza, en el cual se ubican las sociedades coloniales, permitirían captar esa esencia humana que se esconde tras el denso ropaje de la cultura. Según Virchow, capitanes de barco podían recopilar la información requerida si se les orientaba con un simple cuestionario. Esa pasión por la materialidad de la cultura se tradujo en indiferencia hacia el estudio sistemático de la diversidad social del "mundo natural" (Zimmerman, 2001)3. No obstante, ello no significa que las visiones de Bastian y Virchow fueran aceptadas sin resistencias. Heymann Steinthal y Moritz Lazarusen de la Sociedad Antropológica de Berlín, siguiendo la tradición humanista prevaleciente en el mundo germano durante la mayor parte del siglo XIX, intentando hacer valer la importancia de los estudios

3 Es Emil Stephan quien, en la primera década del siglo XX, inicia la práctica del trabajo de campo en el Pacífico. En la región denominada por los alemanes Neu-Mecklenburg, los dos antropólogos entrenados, Edgar Walden y Otto Schlaginhaufen, se dedicaron a recolectar artefactos y esqueletos. En cambio, Stephan, quien no tenía la formación académica de sus acompañantes, se propuso conocer a los nativos mediante la convivencia. La experiencia de Stephan acabó abruptamente a causa de su muerte y no hubo, en el corto plazo, quien le sucediera.

Cuadernos de Antropología 2014, 24(2), 3-24 
lingüísticos, pues sostenía Steinthal, "la lengua no es solo un simple aspecto de la actividad mental humana sino también es un medio de representación"4 (Zimmerman, 2001). Sin embargo, sostiene Zimmerman, estas voces quedaron marginadas. Su impacto en la hegemonía de la perspectiva antihumanista, objetivista de Bastian y Virshow, fue muy limitado.

No obstante, en América Latina, intelectuales alemanes desarrollaron un interés especial por describir y reflexionar sobre las diversas culturas indígenas. Si bien el culto al objeto se impone en los importantes centros de estudios etnográficos como Berlín y Hamburgo, la profusa indagación que Gerdt Kutscher (1976) realiza sobre los estudiosos americanistas vinculados con Berlín evidencia que estos se preocuparon sistemáticamente por explorar las lenguas, las especificidades culturales y, muy especialmente, sus concepciones de la espiritualidad.

En Guatemala, migrantes alemanes que llegaron atraídos por el auge del café de finales del siglo XIX y principios del XX, tales como Karl y David Sapper, se asombraron al encuentro con las otredades del altiplano y tradujeron tal asombro en estudios arqueológicos, lingüísticos y etnográficos. Así, tuvieron un papel hegemónico e incluso, podría decirse, paternal en las nacientes organizaciones y sociedades locales orientadas a los estudios de la historia y la contemporaneidad de la diversidad cultural guatemalteca ${ }^{5}$.

\section{Los antropólogos estadounidenses en Guatemala}

Hacia mediados de la década de 1930, investigadores estadounidenses empezarán a prevalecer sobre los alemanes. De acuerdo con Margarita Bolaños y Jane Adams (1996), la antropología estadounidense deriva de dos corrientes: una de tradición boasiana, interesada en las particularidades culturales de los grupos étnicos, más que en las estructuras sociales y económicas, y la otra muy influenciada por el funcionalismo. Esta última prevalecerá en los estudios antropológicos estadounidenses analizados en páginas posteriores. En ella tuvieron influencia decisiva, intelectuales claves en el desarrollo de la sociología, tales como Max Weber y Durkheim. Según Bolaños y Adams (1996), tres instituciones serán el foco de su interés: el mercado y los sistemas de intercambio, la cofradía y los municipios. Estos autores introducen como eje analítico, la dualidad sociedades modernas y sociedades tradicionales, que será foco fundamental de análisis de los intelectuales latinoamericanos que liderarán en las décadas siguientes las propuestas reformistas en América Latina. Mientras que los representantes diplomáticos alemanes de inicios del siglo XX se ocuparon de promover la exhibición de los objetos arqueológicos y etnográficos en sus museos, los antropólogos estadounidenses se orientaron a estudiar las culturas indígenas en aras de transformarlas ${ }^{6}$. Los

\footnotetext{
4 Traducción de la autora
}

5 Erwin P. Diesseldorff (1926) ofreció una conferencia en la Sociedad de Geografía e Historia de Guatemala con el fin de inducir a su público "a tomar interés en los estudios arqueológicos de su país". Un estudio de la Sociedad de Geografía e Historia puede encontrarse en Palma (1995).

6El desarrollo de los estudios antropológicos y arqueológicos estadounidenses contó con un significativo apoyo institu- 
estudiosos estadounidenses constituyen un grupo bastante bien articulado que, como se analizará adelante, tendrá una apreciable capacidad de influencia sobre las políticas públicas relativas al mundo indígena, en particular aquellas emanadas de la Revolución de 1944, orientadas a la construcción de una identidad nacional. Esta, en la medida de lo posible, integraría al indígena a la sociedad guatemalteca sin generar violentas disrupciones identitarias. Como se verá en este capítulo, instituciones, como el Instituto Indigenista, tendrán un papel central en la construcción de políticas integracionistas. La experiencia de intelectuales extranjeros será incorporada en las prácticas relacionales entre funcionarios del estado e indígenas ${ }^{7}$. Como parte del proyecto de la Revolución de 1944, surge el Seminario de Integración Nacional en el cual participan intelectuales guatemaltecos interesados en promover el estudio del indígena en aras de construir mecanismos consensuales que posibiliten su integración a la ciudadanía. Robert Redfield tendrá un papel significativo en el desarrollo de la antropología en Guatemala. Él junto con otros estudiosos de los grupos étnicos guatemaltecos construirán una red de investigadores que contará entre sus soportes institucionales con la Universidad de Chicago y la Institución Carnegie (Blanchette, 2010).

Las siguientes páginas se abocarán a explorar las distintas miradas sobre la otredad en el altiplano guatemalteco. Se han escogido dos visiones de etnógrafos alemanes que representan lecturas muy distintas del mundo indígena, tributarias de las corrientes antropológicas prevalecientes en Alemania a inicios del siglo XX: la primera, representada por Termer (1957) es una mirada que claramente se impone desde una posición de poder que define a quien es objeto de representación. La segunda, representada por Schultz-Jena, como lo propusiera Steinthal, en la Sociedad Antropológica de Berlín décadas atrás, se interesa por ingresar en la cultura explorando las significaciones del lenguaje.

\section{Una alteridad distante}

Franz Termer (1957), autor de Etnología y etnografía de Guatemala, fue socio activo de la Sociedad de Geografía e Historia de Guatemala y llegó a ocupar el cargo de director del Museo Etnográfico de Hamburgo $^{8}$. Señala Wolfgang Haberland (1995) que Termer realizó investigaciones en Guatemala debido a la influencia que sobre él ejerció el famoso científico y estudioso de la etnografía y vulcanología, Karl Sapper ${ }^{9}$. Haberland (1995) refiere a la influencia que, a través de Sapper, ejerciera en él el determinismo geo-

cional. Ya en 1914, la Institución Carnegie, gracias a la intervención de Sylvanus Morley, realizó estudios arqueológicos en Guatemala, precisamente en el momento en que crecía el interés por explorar el mundo cultural ancestral y contemporáneo de México (Adams y Bolaños, 1996).

7 Como sostiene Thaddeus Blanchette (2010), la experiencia del "panamericanismo indigenista" que se expresa en la conformación de institutos indigenistas en los países del continente es un proyecto claramente vinculado con la política de buena vecindad ensayada por Estados Unidos en América Latina en su lucha contra la expansión del fascismo. Asimismo, la antropología aplicada ensayada ya en los treintas en la Office of Indians Affairs es fundamental en la construcción del indigenismo latinoamericano. 8 Franz Termer era director del Museo Etnográfico de Hamburgo en 1937 cuando, por iniciativa de Elly von Khulmann, viuda del exministro alemán en Guatemala, se inauguró en este una exposición de telas indígenas guatemaltecas (León, 1938).

9 Sin embargo, sus intereses geográficos, científicos, arqueológicos y etnográficos también lo llevaron a la península de Yucatán,

Cuadernos de Antropología 2014, 24(2), 3-24 
gráfico de Friedrich Ratzel. No obstante, también menciona la incidencia que en él tuvieron construcciones más matizadas y complejas de la interacción entre el ser humano y el medioambiente como la de Julian H Steward. Sin embargo, el mismo Haberland insiste en la escasa formación teórica ofrecida por las universidades alemanas y, en particular, en los diversos intereses de estudio de Termer, dentro de los cuales la etnología no ocupaba un lugar privilegiado. Como se vio en páginas precedentes, el mundo alemán a la vuelta del siglo XX, en particular aquel ubicado en una ciudad caracterizada por su dinamismo en el desarrollo de la etnografía: Berlín, en términos generales concentró buena parte de su quehacer en el trabajo de recolección y clasificación de objetos. En esta óptica, la información requerida para situar las diversidades culturales del mundo colonial era básica y no necesitaba de un adiestramiento especial. Ello en buena medida contribuye a explicar por qué la lectura de la obra de Termer parece más cercana a la narrativa del viajero o bien, de un empresario extranjero, que aquella que ya empieza a hacerse manifiesta en su época: la del observador participante (Clifford, 1995). Termer ofrece una descarnada mirada colonial, distante de los métodos etnográficos, los cuales bajo la influencia de Bronislaw Malinowski, abogan por un investigador que se integra, participa en la comunidad estudiada y lleva un diario que le permite sistematizar sus observaciones. Como se verá adelante, los antropólogos estadounidenses tampoco se preocupan por problematizar su posición frente a la alteridad, por el contrario, mantienen un prudente distanciamiento de sus objetos-sujetos de estudio. Termer (1957) refiere en términos positivos a la observación de E. P. Dieseldorff, quien señala que:

En Guatemala el etnógrafo moderno debiera radicarse como negociante, comerciante o finquero, aprendiendo al mismo tiempo alguna de las lenguas indígenas. De lo contrario, siempre será necesario servirse de lo que más o menos puedan comunicar otras personas que se encuentren en la situación deseada (p. 158).

El etnógrafo que domine la lengua de la etnia estudiada ya no dependerá de informantes bilingües elegidos especialmente para este misión, pues podrá comunicarse directamente con el conjunto de la comunidad bajo análisis. Sin embargo, ello no significa que Termer proponga una integración del investigador en la comunidad. La distancia jerárquica entre las ocupaciones propuestas para aquellos interesados en el trabajo de campo y sus objetos de estudio coloca al investigador como agente externo y privilegiado en relación con el indígena. Es altamente probable que esta concepción metodológica limitara su capacidad de acercamiento a la alteridad, no solo por su concepción objetiva, exteriorista de la investigación, sino también por su diametralmente opuesta posición como sujeto frente a la alteridad. El autor posee un punto de vista bastante congruente con el de las elites hegemónicas. Valora la ladinización como elemento positivo e ineludible en el proceso modernizador que terminaría por destruir las diferencias culturales. Sin embargo, esta, desde su perspectiva, lamentablemente encuentra obstáculos en "la actual población indígena perezosa e indolente..." (Termer, 1957). Desde su perspectiva, los indígenas no tienen intención de cambiar,

El Salvador y Honduras (Haberland, 1995).

http://revistas.ucr.ac.cr/index.php/antropologia 
pues ni siquiera perciben "la coerción como yugo" ya que, desde el período colonial, estuvieron habituados a vivirla. Otorga coherencia a esta afirmación sosteniendo, con base en Thomas Gage, que sus gobernantes fueron exterminados por los españoles y "lo que quedó de la raza fue la masa de la clase dependiente" (Termer, 1957). Esta afirmación, que permite al autor distanciar a los habitantes indígenas contemporáneos de las complejas culturas ancestrales mayas, no se sostiene ante la evidencia histórica de la complejidad de la conquista y, en particular, de las distintas estrategias que ensayaron los españoles para establecer su dominio, entre las cuales prevalecieron las alianzas con la antigua clase dominante (Kramer et al., 1994). Agrega Termer que "esta gente no siente tal coerción como yugo" (Termer, 1957, p. 251), aunque reacciona con manifestaciones violentas cuando esta es llevada a límites insoportables. En la perspectiva del autor, el indio soporta su situación porque está conforme con ella y no porque carezca de alternativas ${ }^{10}$. La adaptación a relaciones de poder que no hay posibilidad de revertir se convierte, desde esta perspectiva, en una característica identitaria inmutable, en un estereotipo que comprende a la diversidad de etnias del altiplano.

El autor indaga sobre la "brujería", etiqueta que aplica a las manifestaciones espirituales indígenas que tienen lugar al margen de la iglesia y escapan al ojo vigilante de los sacerdotes católicos ${ }^{11}$. Su interés por estas prácticas lo llevan a espacios culturales que los indígenas celosamente resguardan de los extraños. Termer reflexiona sobre su trabajo etnográfico, pues resiente la distancia que el indígena impone recurriendo incluso a la intimidación del investigador. Sin embargo, él genera estrategias para acercarse a las dimensiones culturales mantenidas, según asevera, en secreto. En efecto, recurrentemente en el texto, alude a los "secretos" de sus objetos-sujetos de investigación. El "secreto" se alza como una muralla que limita su acceso a los rituales propios de la espiritualidad, pues "casi siempre es negada la información y ocasionalmente también se proporcionan indicaciones inexactas" (Termer, 1957, p. 157). Schultze-Jena, estudioso de los quichés cuya obra se analizará adelante, a diferencia de Termer, se preocupa por ingresar a las significaciones de los ritos religiosos y mágicos, cuya diferencia establece a partir de las definiciones dadas por la comunidad que estudia. Se advierte en su texto que él construyó una relación de mayor fluidez con el universo estudiado y, quizá por ello, "el secreto" no es tema que le perturbe. Quizá bajo la influencia de los ladinos, Termer expresa temor ante las potenciales manifestaciones de descontento del indígena, narrando historias sanguinarias en las que sus objetos-sujetos de investigación torturan y matan a quienes se atreven a violar sus altares clandestinos y sus rituales secretos. Él crea estrategias para acercarse a dicha ritualidad: disimuladamente, subrepticiamente, asumiendo el disfraz de un transeúnte que pasa por allí de casualidad; nunca se presenta como observador, pues, de hacerlo, el riesgo menor consistiría en que el espectáculo que tanto le ha costado llegar a presenciar fuera abruptamente interrumpido. Desde su perspectiva, la "brujería"

10 Solo cuando se llega al límite de lo tolerable acude a estrategias de movilización social, las cuales pueden tener resultados desastrosos para la comunidad, pues, de acuerdo con la experiencia histórica, es altamente posible que el Estado vuelque la fuerza de su aparato represivo sobre los sublevados (Termer, 1957).

11 "La brujería, por su parte que abarca la creencia popular y la superstición, la hechicería y adivinación, el exorcismo y las curaciones, domina hoy las ideas religiosas del indígena de Guatemala y de las partes colindantes de México [...] es difícil hacer algo contra este fecundo maremágnum de creencias extrañas...” (Termer, 1957, p.156).

Cuadernos de Antropología 2014, 24(2), 3-24 
es un mal que subsiste por la incapacidad de los sacerdotes de imponer su autoridad a los indígenas, representados en su texto como sujetos extremadamente violentos cuando agentes externos intervienen en sus costumbres.

Termer es básicamente un observador que transmite los actos observados. Cuando refiere al ritual de la muerte, describe el proceso que se aplica al cadáver, el lugar donde es colocado, las flores y las velas que lo rodean, las oraciones que corresponden al brujo, cómo se entierra el cadáver, la bebida de aguardiente que precede el entierro, etc. (Termer, 1957, p. 108). El escritor expresa lo que observa desde una mirada noratlántica teñida por la perspectiva ladina. La coherencia de su relato, a partir de la secuencia de los acontecimientos en el tiempo, se pierde en el sinsentido de narraciones de eventos carentes de significación.

\section{Lenguaje y subjetividad: penetrar la alteridad para aprehenderla desde sus propios referentes}

En 1945, los Anales de la Sociedad de Geografía e Historia de Guatemala publican por primera vez la obra del Dr. Leonhard Schultze-Jena (1954), La vida y las creencias de los indígenas quichés de Guatemala, la cual data de $1932^{12}$. El autor realiza investigaciones en el continente americano gracias al apoyo de la Sociedad Científica de las Necesidades Económicas Alemanas. Inicialmente planeó llevar a cabo un estudio integral de arqueología, geografía y etnología en territorio mexicano junto con el Dr. Walter Lehmann. No obstante, renunció a este proyecto, entre otras razones porque en su criterio este país, pese al comercio clandestino de piezas arqueológicas, todavía conserva bastantes tiestos y monumentos bajo tierra. De acuerdo con su valoración, "es mayor el peligro que amenaza a los rasgos espirituales de la antigua cultura indígena, a la tradición del pueblo y al vehículo que la transmite, el idioma” (Schultze-Jena, 1954 , p. 14) $)^{13}$.

12 El Instituto Indigenista de Guatemala publica en 1947 y reedita en 1954 esta obra. Para la presente investigación se consultó esta última edición. Biblioteca de Cultura Popular. Vol. 49. Dr. Leonhard Schultz Jena, La vida y las creencias de los indígenas quichés de Guatemala. En la edición de 1947, la introducción de los traductores, Antonio Goubaud Carrera y Herbert D. Sapper fue ampliada y modificada. Este texto apenas contiene una parte del trabajo realizado por Schultz- Jena. No se publican las relaciones que el autor recogiera de los propios indígenas, las cuales integran la tercera parte de la obra. La misma suerte corre el extenso vocabulario analítico con las voces y giros gramaticales con sus equivalencias en alemán. Tales exclusiones constituyen una falencia en un texto que es integral. En el cuerpo central de la etnografía, el autor recurre frecuentemente a estas para apoyar su análisis. La edición de 1947 fue posible gracias a la Institución Carnegie de Washington, al Instituto Indigenista Nacional y a la Sociedad de Geografía e Historia de Guatemala. Antonio Goubaud Carrera y Herbert D. Sapper fueron los traductores. También esta publicación contó con el apoyo de la Escuela Nacional de Antropología e Historia de México, la cual ofreció una copia de la traducción. Ello parece indicar que dicho instituto financió la publicación. En el preámbulo de su libro en alemán escrito en 1932, Schultz-Jena agradece al señor W. von Kuhlmann haber contribuido al resultado de esta investigación; a Walter Lehmann, por su ayuda para consultar el Instituto de Etnología de Berlín; al Dr. Gustav Fischer, por editar su libro en Alemania. Marbug, octubre de 1932.

13 Sin embargo, años más tarde, realiza investigaciones en Guerrero, cuyos resultados recoge en la obra Entre los aztecas, mix- 
Convocado por un investigador alemán de larga experiencia en el contexto mesoamericano, SchultzeJena todavía pertenece a una generación de estudiosos de las culturas indígenas que, lejos de circunscribirse a especialidades, combina en su quehacer investigativo diferentes áreas de conocimiento. Gracias a la indagación de Johanna Broda (2008), se sabe que estudió a finales del siglo XIX en Lausanne, Jena y Kiel, medicina y ciencias naturales, se tituló en Zoología e hizo estudios de Botánica. Ocupó la Cátedra de Geografía en la Universidad de Marburg/Lahn, en Alemania, donde introdujo sus conocimientos de Lingüística, Zoología y Etnología, de la que llegara a ser su área de mayor interés a partir de la década de 1920: Mesoamérica.

La concepción de Schultze-Jena del trabajo etnográfico, del papel de la lingüística en este, y de la relación del estudioso con su universo de análisis, es radicalmente distinta a la de Termer; no arribó al altiplano con un método preconcebido. Estudió la cultura indígena para generar estrategias que le permitiesen "penetrar" en ella. Asimismo, se acercó a esta estableciendo relaciones amistosas pues:

[...] el indígena se expresa cuando siente confianza. No gusta de cosas abstractas, prefiriendo mostrar la evidencia que proviene de su propia experiencia... Resuelve dramáticamente la acción por medio del diálogo y la facilidad con que le fluye la palabra siempre que usa este método de expresarse es sorprendente (Schultze-Jena, 1954, p. 15).

A diferencia de de Termer, se encuentra con un sujeto locuaz, expresivo y amigable con el investigador. Pero este también se valió de un informante clave para acercarse e ir ganando la confianza de la comunidad, el cual, probablemente, al menos en un inicio, le sirvió de traductor. Su indagación sobre la comunidad tiene como punto de partida el lenguaje, es decir, a través del análisis del lenguaje se propone ingresar a la cultura. Por ejemplo, cuando habla de la integración de las cofradías, refiere entre otros cargos a aquellos que ocupan los och'op y el cual "según parece, en tiempos antiguos, este oficio pareció ser el de un elevado ayudante de sacerdote, quien lo instruía en la lectura, en la escritura y aun en el latín... o'chóp deriva de ch'obik, pensar, o sea por sus ocupaciones intelectuales estos individuos son estimados por la comunidad" (Schultze-Jena, 1954, p. 39). El indígena, sostiene el autor, "no conceptúa la separación del cuerpo y del alma, en la forma como nosotros la entendemos. En su idioma no existe la palabra para lo que nosotros llamamos 'alma'”' (Schultze-Jena, 1954, p. 50 ).

Schultze-Jena no espera obtener respuestas en sus propios términos. Por este motivo, indaga en su discursividad y en las particularidades de su lengua para hilvanar una cultura que concibe como cualitativamente distinta. De esta forma, intenta dejar de lado las jerarquizaciones étnicas y, en particular, los estereotipos de las comunidades ladina y de los inmigrantes alemanes, para ingresar al sentido mismo de sus

tecos y tlapanecos de la Sierra Madre del Sur de México, publicada en 1938 en alemán -el título de la obra ha sido traducido al español por Johanna Broda-. Hacia mediados de la década de 1930 había realizado investigaciones en el occidente de El Salvador (Broda, 2008, pp.118 y 122). 
prácticas sociales ${ }^{14}$. Es sorprendente que, pese a su extraordinaria agudeza para analizar el mundo de los otros en sus términos a partir de la exploración del lenguaje, este profesional no recibió ninguna formación universitaria en la etnografía y la lingüística (Broda, 2008); sin embargo, contó con una amplia experiencia en el desarrollo de estos campos. Ya en 1911 había estudiado la población de la isla Tumleo, donde aprendió el melanesio y escribió un libro sobre esta lengua. Su sensibilidad para penetrar en mundos tan disímiles a aquel del que provenía podría sugerir que se nutrió de los trabajos de sus contemporáneos Bronislaw Malinowski y A. R. Radcliffe-Brown. No obstante, Broda (2008), quien explora su periplo como investigador etnográfico, señala que nunca entró en contacto con ellos y que no existen rastros de que los haya leído. Es evidente que en Schultze-Jena se encuentra la novedosa "sensibilidad etnográfica" de su época. Desdichadamente, no se cuenta con reflexiones sobre su estrategia investigativa; sin embargo, su preocupación por interpretar las sociedades estudiadas desde sus propios parámetros, su interés en dominar la lengua no solo para comunicarse, sino también para aprehender los sentidos más fundacionales de la cultura, el tono de familiaridad y de cercanía con el que narra esas otredades, sugieren que logró integrarse (o al menos intenta mostrar a los lectores que lo hizo), participar en la comunidad y ganar la confianza de sus miembros ${ }^{15}$.

La divinidad que se implora bajo el nombre de Juyúptik'aj, explica Schultze-Jena, se aparece en la forma de un mo'x, pues, asevera el etnógrafo "solamente el que delira genuinamente es el que ve esta figura. Ahora bien, ella es real porque en sus visiones fantásticas, el indio alcoholizado se siente más próximo a dicha divinidad" (Schultze-Jena, 1954, p. 54) ${ }^{16}$. En cambio Termer, en relación con el significado del alcohol en la ritualidad indígena, observa que "antes del entierro... beben grandes cantidades de aguardiente, de manera que finalmente acompañan al féretro con grandes gritos y lamentaciones exageradas." Finalmente "todos regresan a casa a dormir la borrachera" (Termer, 1957, p. 110). La mirada de Termer no difiere en mucho de aquella prevaleciente entre los sectores hegemónicos guatemaltecos. Su identidad "amurallada" en "la cultura superior", difícilmente puede ir más allá de la reproducción del estereotipo del indio alcohólico. En su acercamiento al otro, Schultze-Jena descubre nuevas expresiones de la "verdad" en rituales que la modernidad valora como producto de creencias ingenuas, carentes de fundamento. Refiriéndose al adivino señala: "Bajo los efectos de una ligera intoxicación, vagando horas enteras por los montes, se puede orar a la divinidad" (Schultze-Jena, 1954, p. 92). Esta frase sugiere que el investigador se ha propuesto expresarse en términos que manifiesten la experiencia del otro.

14 De acuerdo con Broda (2008), "mediante el estudio de la estructura de lenguas desconocidas, Schultze-Jena se propuso penetrar en el pensamiento y los conceptos de los pueblos respectivos".

15 Clifford (1995) describe este "proceso de internarse en un universo expresivo extraño... [como] un activo 'sentirse en casa' en un universo común" (Clifford, 1995, p. 55). La observación participante, según Clifford, expresa la experiencia subjetiva del etnógrafo, pero no necesariamente una experiencia intersubjetiva, dialógica, perspectiva que privilegia en su estudio crítico del trabajo y la escritura antropológica".

16 Las itálicas son propias. 
En su trabajo se encuentran expresiones como "Los indios quichés consideran que... estiman que..." (Schultze-Jena, 1954, p. 21), “... creen firmemente...” (Schultze-Jena, 1954, p. 92), “piensan que...”. Más que por los actos o eventos, se interesa por las emociones que a estos acompañan. La dimensión mágica es explorada a través de los temores y angustias experimentadas frente a las señales del destino, sino que deberán descifrar los adivinos (Schultze-Jena, 1954, p. 84). De nuevo, la experiencia es representada como parte del universo "real" de los sujetos. La enunciación no es patriarcal ni autoritaria, más bien transmite la imagen de un hombre que, fascinado frente a la diferencia, se empeña más que en posesionarse de su conocimiento, en ser partícipe de este. La experiencia se impone a la descripción.

Detecta oraciones que incorporan elementos del cristianismo, como por ejemplo "é na káukristo, k'o par i santísima gloria... [pero, asevera, se trata de simples expresiones ya que] "los indios intercalan estos giros entre sus ideas paganas en forma tan desvinculada de ellas que no vale la pena subrayarlas cada vez que se presentan" (Schultze-Jena, 1954, p. 105 )... [para el autor, solo se aprecia una aceptación] "más sólida de los beneficios de la iglesia" (Schultze-Jena, 1954, p. 105), en el bautismo y en el culto a los santos que se encuentra influenciado por las nociones del indígena sobre el destino.

En síntesis, si Shultze-Jena realizase su estudio en estos tiempos, encontraría más acorde un concepto como el de heterogeneidad propuesto por Cornejo-Polar que el de mestizaje, para referir a la religiosidad indígena. No se está ante una mezcla de dos culturas que conduce a la síntesis del mestizaje. Los elementos cristianos cubren una espiritualidad profundamente distinta. Se trata de una discursividad que "acumula, sin sintetizarlas, sus hondas y extensas contradicciones" (Cornejo-Polar, 1994, p. 283) ${ }^{17}$. Desde una perspectiva, externa, objetivista, mucho menos atenta a las significaciones discursivas, el antropólogo Robert Redfield en su artículo "La cultura y la educación en el Altiplano Medio-Occidental de Guatemala"18, al analizar la ritualidad de los habitantes de la aldea de San Antonio, encuentra "más forma que contenido en su vida colectiva" (Adams, 1956). Los ritos, aunque carentes de "significado simbólico, sí contribuyen a preservar las costumbres tradicionales... Los dramas-danzas ilustran de manera evidente el aspecto relativamente formal o externo de gran parte de las culturas guatemaltecas" (Adams, 1956, pp. 222-223). Estas representaciones se encuentran en un "español retórico" por lo que "es raro que un indígena se dé plena cuenta de lo que está diciendo" (Adams, 1956, p. 223). La danza se ejecuta porque hay personas dispuestas a invertir tiempo y dinero en hacer algo para alegrar la fiesta. Precisamente, en esas expresiones culturales "carentes de significado" para Redfield, es donde Schultze-Jena encuentra la densidad de la cultura, deformada e incluso invisibilizada por una mirada occidental atrapada en sus propios parámetros.

17 Refiriéndose a Garcilaso, Cornejo-Polar señala que "la convergencia homogeneizante que cuidadosamente se teje en el discurso explícito, como discurso de la armonía, se deshila en el subyacente, apenas implícito, donde lo vario y contradictorio, lo heterogéneo, reinstala su turbadora y amenazante hegemonía" (Cornejo-Polar, 1994, p. 99).

18 Varios artículos de esta compilación serán analizados adelante. Este artículo de Redfield así como buena parte de los incluidos en este volumen es previo a la revolución guatemalteca de 1944, la cual, como también se analizará adelante, tuvo una incidencia significativa en la perspectiva de los estudiosos estadounidenses sobre las comunidades indígenas.

Cuadernos de Antropología 2014, 24(2), 3-24 


\section{Modernización y tradición en las comunidades indígenas}

La compilación Cultura indígena de Guatemala. Ensayos de Antropología Social realizada por Richard Adams y publicado en 1956, contiene una serie de investigaciones sobre las sociedades indígenas guatemaltecas realizadas en su mayor parte a lo largo de las dos décadas precedentes por intelectuales estadounidenses especializados en antropología social, con las excepciones de los estudios de Sanford Mosk, economista, y Melvin Tumin, sociólogo ${ }^{19}$. La presencia de la comunidad intelectual guatemalteca está representada en la figura de Antonio Goubaud Carrera, único autor que no proviene de la sociedad estadounidense. El libro se compone especialmente de traducciones de artículos publicados en revistas norteamericanas. La compilación misma así como los diálogos que los estudiosos incluidos en esta establecen entre sí en sus investigaciones, muestran el desarrollo de una comunidad de intelectuales estadounidenses ocupados del mundo indígena guatemalteco.

El proceso de especialización en los estudios sociales que vive la academia estadounidense durante las primeras décadas del siglo xx se hace patente en esta obra ${ }^{20}$. La influencia de la sociología se aprecia con claridad en buena parte de las obras incluidas en la compilación realizada por Adams. Estas parten del planteamiento de problemáticas sociales por resolver, las cuales, recurrentemente, están vinculadas con el papel de las sociedades indígenas en la vida social y económica de la nación. Según Adams y Bolaños (1996), entre las décadas de 1930 y 1940, buena parte del interés de los antropólogos estadounidenses giró en torno a las diferencias entre las sociedades modernas y tradicionales, es decir, atrasadas desde la perspectiva del ideal del progreso. Dichas investigaciones indagaron los procesos de cambio social, por lo que estuvieron a tono tanto con los proyectos integracionistas que toman fuerza en Guatemala a partir de la Revolución de 1944 como con los proyectos desarrollistas impulsados por la Cepal. Estos últimos, bajo la influencia de Talcott Parsons, tuvieron como eje central la teoría de la modernización. Los artículos de Redfield y de Tax fueron publicados originalmente en inglés en 1939 y $1941^{21}$, respectivamente, es decir, en un período previo a aquel signado por el diseño de políticas para la transformación del mundo de la posguerra. Sin embargo, como lo establece Blanchette (2010), la antropología estadounidense de estas décadas tuvo una fuerte influencia de la antropología aplicada que, con el fin de integrar el mundo indígena a la modernidad, se ensayó desde la Oficina de Asuntos Indígenas ya en la década de 1930 y, especialmente, en la de 1940. De tal forma, sostiene, "el trabajo de los antropólogos sobre las reservas indígenas en los Estados Unidos prefiguró en gran medida, tanto en perspectiva filosófica como técnica, la actual antropología del desarrollo"

19Edición a cargo de Jorge Luis Arriola. El libro informa que en el consejo consultivo del Seminario de Integración Guatemalteca se encuentran figuras relevantes en los estudios de la cultura indígena como Hugo Cerezo Dardón, Vicente Días Samayoa, Jorge Skinner-Klée, David Vela. La Secretaría General la ocupa el ya veterano intelectual Jorge Luis Arriola.

20 Como lo sostienen Matei Dogan y Robert Pahre (1990), analizando la oferta curricular de importantes universidades estadounidenses como Harvard y Berkeley, en la década de 1920, lentamente se desarrolla los estudios antropológicos como campo de especialización.

21 Se conocen las fechas en que se publicaron estos artículos en inglés porque son citados en artículos de la compilación. Véanse las notas 10 en: Tax (1947) y Mosk (1956). 
(Blanchette, 2010, p. 51). Los trabajos de Redfield y Tax muestran la importancia que en la vida académica de Estados Unidos tenía ya para entonces el tema del desarrollo del mercado interno en América Latina. Los tres autores: Redfield, Tax y Mosk comparten una problemática común de análisis: la coexistencia en las comunidades indígenas de una dimensión moderna con otra tradicional. Esta concepción no deja de remitir a los planteamientos cepalinos, fundamentados en la dualidad centro-periferia. Desde esta perspectiva, un eje modernizante y dinámico -el centro- encuentra limitaciones para integrar una dimensión de atraso, pobreza y escaso dinamismo económico -la periferia- (Rodríguez, 1989). En estos últimos espacios, dada la existencia de una estructura económica que reproduce la desigualdad, la total modernización de la vida social y económica, debe de responder a un proyecto planificado desde el Estado.

Las influyentes tesis de Redfield y Tax problematizan las construcciones de las sociedades arcaicas encontrando en ellas un elemento clave de modernidad en el mercado ${ }^{22}$. En sus obras existe un diálogo implícito con el análisis "weberiano" que conduce a interpretaciones novedosas (Weber, 2006). Si bien de acuerdo con Max Weber la ética protestante es la impulsora de las transformaciones que conducen al capitalismo, en la perspectiva de estos estudiosos de las comunidades del altiplano, el desarrollo mercantil, identificado como elemento clave del capitalismo, no está en concordancia con la dimensión cultural, más bien el dinamismo económico expresado en la mercantilización de la economía tiene lugar a pesar de que el universo tradicional de la cultura indígena se mantiene incólume. Por tanto, el mercado en este caso carece de la fuerza necesaria para dinamizar y poner a las comunidades del altiplano a tono con la modernización mercantil. Es decir, la dualidad modernidad-tradición comparte una misma dimensión espacial y subjetiva, sin que los elementos modernos, a diferencia de lo que según Weber ocurrió durante el desarrollo del capitalismo, se impusieran sobre los tradicionales. Esos sujetos deseosos de hacer negocios contrastan con sus arcaicas formas de percepción del mundo. La mercantilización del indígena tiene parangón con aquella prevaleciente en sociedades modernas. Sin embargo, lejos de transformar una mentalidad considerada arcaica, convive con esta sin causarle alteraciones significativas. En dicha dirección, la polaridad atraso-modernidad se distancia de aquella que prevalecerá en las tesis desarrollistas, las cuales ubicaban las limitantes al proceso de modernización en las estructuras socio-económicas (Rodríguez, 1989). En cambio, para los autores estudiados la polaridad modernidad-atraso se resume en la polaridad mercado-cultura.

Mosk, cuyo artículo corresponde a la década de $1950^{23}$, es quien más claramente se ubica en la discusión sobre las sociedades duales, ya en boga por entonces. Intelectuales a cargo de diseñar las transformaciones económicas de las siguientes décadas concibieron el desarrollo del mercado interno como el elemento clave en la modernización de las economías del mundo pobre, proceso que, por antonomasia, conduciría a un mejoramiento de las condiciones de vida del conjunto social. El crecimiento de la capacidad de consumo,

22 De acuerdo con Margarita Bolaños (1999), en las décadas de 1930 y 1940 los estudios de Redfield y de Task tienen una incidencia considerable en la antropología centroamericana.

23 Si bien Adams no ofrece información acerca de previas publicaciones del estudio de Mosk, revisando las citas al pie de página, se descubrió que la más reciente data de 1953. Se trata precisamente de un estudio de Tax, S. titulado Penny Capitalism: A Guatemalan Indian Economy, de 1953.

Cuadernos de Antropología 2014, 24(2), 3-24 
de paso, redundaría en beneficios para las grandes empresas del mundo noratlántico, que encontrarían en las antiguas colonias, mano de obra más barata en nuevos y pujantes mercados. En este contexto, se explica por qué un economista como Mosk (1956) se interesa en temas relacionados con la antropología. El autor critica a los economistas nacionales por cuanto conciben la comunidad indígena aislada de la economía nacional e internacional y plantea la existencia de la especialización y de un vital comercio en los poblados indígenas. Además, advierte que en ese mundo "primitivo" de la cultura, las transacciones se basan en las fuerzas del mercado, no en la costumbre. Concluye señalando que posiblemente sea corto "el camino que tiene que ser recorrido para producir la integración económica de la gente del altiplano" (Mosk, 1956). Sin embargo, se deduce de su estudio, así como de los que le preceden, que no hay una clara relación interactiva entre mercantilización y modernización. De esta forma, el autor discute con las teorizaciones que proponen que América Latina se caracteriza por el atraso en el desarrollo económico [léase mercantil] del mundo rural latinoamericano, factor clave en la problemática de ese nuevo concepto que aglutina a las diversas regiones coloniales: el subdesarrollo. Para superarlo, por tanto, es imprescindible trascender la dualidad social. En el estudio de Mosk, así como en los pioneros estudios de Redfield y de Tax, la problemática del indígena no se encuentra en una eficaz vinculación con el mercado, pues esta ya existe, sino, más bien, en la transformación cultural. De acuerdo con Redfield (1956a), la cultura primitiva del indígena contrasta con su agudo sentido del negocio. La convivencia del atraso cultural con el desarrollo de las relaciones mercantiles constituye una constatación digna de tomarse en cuenta, pues es indicativo de que la mercantilización no está transformando una sociedad en la que se combina "la vida de tribu y un comercialismo muy desarrollado" (Redfield, 1956a, pp. 43-44). Tenemos entonces un mundo de dinamismo mercantil que si bien no encuentra limitaciones significativas en su desarrollo en el terreno cultural, tampoco transforma la dimensión productiva, caracterizada por instrumentos de producción arcaicos mientras construcciones de la naturaleza propias de pueblos primitivos, distancian radicalmente a los agentes sociales de la aplicación de la ciencia a las técnicas de cultivo ${ }^{24}$.

\section{La convivencia modernidad-barbarie}

En la prevaleciente concepción lineal barbarie-civilización, los autores descubren universos mentales primitivos, es decir, cualitativamente distintos a los suyos. Al describir lo que observan sin acercarse a la dinámica propia de la vida del indígena, disocian las transacciones económicas del contexto socio-cultural. Los músicos de las cofradías, por cuanto reciben dinero, son "empleados", lo mismo que los "chimanes", especializados en ofrecer oraciones por otros a cambio de un estipendio en dinero (Redfield, 1956a). Ello es indicativo de que responden a alicientes del lucro. Al valorar la circulación monetaria al margen del contexto, las significaciones más básicas del intercambio mercantil se disuelven a tal punto que Redfield

24 Tax sostiene que: "Esta incorporación [a la vida mercantil] parece no haber tenido efecto alguno en la cultura fundamental, porque, después de todo, está constituida de tal manera que puede hacer esas acomodaciones externas" (Tax, 1956, p. 110).

http://revistas.ucr.ac.cr/index.php/antropologia 
establece fácilmente conexiones entre los agricultores indígenas del Altiplano y los farmers de su país, pues "la agricultura en Panajachel es casi tanto una empresa individual, como lo es en las granjas alrededor de Chicago" (Redfield, 1956a, p. 53). En un similar proceso de abstracción del mundo social frente al intercambio mercantil, Mosk observa que los salarios en las fincas de café contribuyen a la mercantilización sin advertir las violentas transformaciones en las relaciones sociales que tales procesos generaron (Mosk, 1956) ${ }^{25}$. Los tradicionales cargadores, quienes recorren a pie grandes distancias en busca de mercados para los bienes mercantiles que llevan sobre sus espaldas, son representados como el vivo ejemplo de la existencia del homoseconomicus en el corazón del mundo indígena. Mientras Stephens (1982), viajero del siglo XIX, se sintió conmocionado cuando presenció a estos hombres convertidos en animales de carga, desde la perspectiva sociológica modernidad-retraso, se convierten en "comerciantes profesionales" representantes del dinamismo mercantil (Mosk, 1956, p. 70).

En estas reflexiones sobre la sociedad indígena, las particularidades étnicas son apenas aprehendidas por sus signos externos ${ }^{26}$. Posiblemente esa es la razón por la que no hay una problematización de la interacción entre el investigador y sus objetos-sujetos de investigación. El análisis lingüístico está ausente entre investigadores que se proponen retratar lo que observan más que penetrar en busca de los significados propios de la cultura. Mosk (1956) refiere a las "diferencias de lenguaje [como] un serio obstáculo para obtener información”. No obstante, desde esta perspectiva, el problema de lenguaje es concebido como un problema de traducción. Se podría argumentar que su formación de economista no le lleva a plantearse la posibilidad del estudio de las lenguas indígenas. Sin embargo, los antropólogos que le preceden en sus investigaciones tampoco muestran sensibilidad hacia esta dimensión de la cultura. Mosk, al igual que Termer, encuentra que la hostilidad y desconfianza del indígena hacia los extraños son limitantes significativos en la recolección de la información requerida. La sospecha de que esta será utilizada para la imposición de nuevos tributos o trabajos forzados los hace reticentes a colaborar con los estudiosos de sus sociedades (Mosk, 1956). Plantea la distancia con el indígena como irreductible, pero en su óptica se trata simplemente de una variable por tomar en consideración. Tax establece claramente una distancia jerárquica entre él y los indígenas cuando, pese a admirar su capacidad para establecer negocios, asegura que "la visión primitiva es cuantitativamente menor y tiene un alcance más limitado, nosotros sabemos de ellos, pero ellos no nos conocen, y mientras que conocen solamente una porción muy pequeña del mundo, nosotros tenemos algún conocimiento de todo" (Tax, 1956, p. 112). Además de degradar las formas de conocimiento del indígena al compararlas con las de la sociedad civilizada, Tax (1956) descarta toda posibilidad de encuentro interactivo entre él y estos seres primitivos. Una distancia abismal separa la barbarie de la civilización. Pero mientras seres civilizados desde su posición cultural privilegiada pueden conocer al otro, este último, con una visión arcaica e ingenua del mundo natural y social, no puede conceptualizar a esa otredad que le

25 Sobre las relaciones laborales en Guatemala puede consultarse: Taracena y Gellert (2002).

26 Sol Tax (1956) establece las diferencias entre las etnias, señalando que cada municipio tiene su vestido típico, sus costumbres y usos relacionados con el nacimiento y el bautizo, el matrimonio, el entierro, el parentesco, la organización de la familia.

Cuadernos de Antropología 2014, 24(2), 3-24 
es superior. Para este autor, la única forma de conocimiento válida está dada en sus propios términos, pero al negar la capacidad del otro de conocerle, se está negando él mismo la posibilidad de ingresar en los referentes propios de la cultura estudiada ${ }^{27}$. Tax conoce al otro mediante su concepción etnocéntrica del mercado, desvinculada de las formas de explotación del indígena y de sus mecanismos de sobrevivencia. Su visión analítica se fundamenta en la dicotomía sociedad moderna y sociedad tradicional la cual lo conduce a desvincular el intercambio mercantil de la cultura dado que esta última no se ajusta a los estereotipos de las sociedades modernas, sinónimo de sociedades mercantilizadas. La imposición de parámetros de la sociedad moderna externos a la sociedad en estudio ofrece como inevitable resultado un universo de signos incoherentemente articulados. Miradas focalizadas en una institución mercantil totalmente desligada de los procesos socio-culturales y, en particular, de las luchas cotidianas por la sobrevivencia, construyen una distancia jerárquica insalvable entre el universo de los investigadores y aquel de los objetos-sujetos de estudio.

\section{La antropología y la integración del indígena a la sociedad guatemalteca}

La revolución guatemalteca de 1944 ponía fin a la férrea dictadura de Jorge Ubico e introducía por primera vez en el país, políticas de reforma social en beneficio de las mayorías. Sus líderes encontraron en el indigenismo herramientas para incorporar el mundo indígena, postrado en la miseria y exclusión, a la ciudadanía. Se intentó sustituir mediante reformas políticas y laborales modernas, las formas clientelares que con relativo éxito ensayara Ubico sobre una población indígena sometida aun en pleno siglo XX a relaciones labores compulsivas. Como normalmente lo han pregonado los estados modernos, la construcción de una cultura compartida fue concebida por los líderes del cambio, como una necesidad histórica en la invención de la nación. Siguiendo el espíritu del indigenismo, apoyaron la formación del Instituto Indigenista Nacional en busca de los mecanismos más apropiados para integrar al indígena a la sociedad hegemónica. Goubaud fue el primer director del Instituto Indigenista, fundado en 1945, con su activa participación junto con David Vela y Carlos Antonio Girón (González-Ponciano, 1989).

Abigael Adams (2008) muestra el papel protagónico que en esta época tuvieron antropólogos estadounidenses como Redfield y Tax no solo en las primeras fases del Instituto Indigenista Nacional (IIN), sino también en la formación misma de su primer director, Goubaud Carrera, quien obtuvo, en buena medida gracias a los buenos oficios de ambos investigadores, su maestría en Antropología en la Universidad de Chicago. No obstante, Goubaud ya en la década de 1930 contaba con experiencia en el campo etnográ-

27Redfield (1956a) considera la espiritualidad indígena como expresión de una visión ingenua, cuando señala que en su percepción de mundo "la lluvia no es solo lluvia, sino el agua que da la vida derramada desde el cielo por doce ángeles" (1956a, p. 45). Mientras el arco iris sirve para esconder serpientes malignas, los rayos las buscan para destruirlas. Basta que abandonen su municipio para que se perciban a sí mismos como extranjeros. Con estos ejemplos, el autor advierte "la substancia de lo que se encuentra en cualquier sociedad primitiva" (1956a, p. 46).

http://revistas.ucr.ac.cr/index.php/antropologia 
fico y para entonces empezó a moldear una visión antropológica particular que no dejó de experimentar la influencia estadounidense, especialmente en los años en que laboró en el IIN. En 1936, manifestaba que "ha llegado el tiempo en que el estudio del indígena se haga a base de una investigación científica de su psiquismo de su vida social de sus creencias religiosas y de su idioma" (Goubaud, 1968, p. xv). En su artículo de 1946, "El grupo étnico indígena. Criterios para su definición”, se propone mostrar que no existen marcadores físicos o culturales predeterminados, pues estos pueden tener variaciones considerables de una región a otra y que, en Guatemala, la sociedad ladina, establece las diferencias a partir de elementos culturales más que físicos. Este descubrimiento le resulta:

Uno de los hechos sociales más afortunados que pueden encontrarse en cualquier país, toda vez que el color de la piel o del pelo no tienen ninguna relación con la inteligencia ni la humanidad del hombre, y que por tanto puede llegarse a una solidaridad social mucho más rápida entre los grupos étnicos de todo el país (Goubaud, 1946, p 30).

En 1949, manifestaba: "Si hemos de alcanzar realmente un mundo bien integrado, creo que debería ser sobre la base de saber cómo piensan y actúan otros pueblos, de manera diferente a nuestro modo de pensar y actuar" (Goubaud, 1964b, p. 208). Goubaud muestra en este artículo el rostro más amable de la antropología aplicada: conocer al otro para integrarlo en los términos menos traumáticos posibles ${ }^{28}$. El autor intenta romper con el binarismo civilización-barbarie, develando las distancias culturales como diferencias cualitativas más que como distancias jerárquicas ${ }^{29}$. Sin embargo, no debe perderse de vista que su trabajo se articula con específicos proyectos políticos que en alguna medida, limitan y definen su óptica de análisis. Durante su gestión hizo prevalecer su formación en la Universidad de Harvard y Chicago, sus estrechos vínculos con antropólogos extranjeros, particularmente estadounidenses e instituciones de este país como la Carnegie. Según Jorge Ramón González-Ponciano (1989), la carencia de cuadros capacitados fue suplida con académicos de Estados Unidos quienes "se hicieron cargo de asesorar e incluso de dirigir trabajos importantes de la política indigenista oficial” (p. 40). Goubaud abrió espacios para que Redfield y Tax desempeñaran un papel hegemónico en el Instituto Indigenista Nacional e impusieran sus perspectivas funcionalistas, junto con el enfoque aplicado de la antropología cuyo fin consistía en la aculturación del indígena (Adams, 2008). Sostiene Bolaños (1999) que el Instituto continuó con las agendas de investigación

28 Abigail E. Adams sostiene que Goubaud "dio muestras de relativismo cultural al referirse a las "dos" culturas, indígena y no indígena como válidas" (2008, p. 88).

29En 1926, el Dr. R. Lehmann-Nitsche, profesor del Museo de La Plata, en Argentina, esencializa la existencia de una supuesta mentalidad de los pueblos primitivos, estableciendo cómodamente parangones entre sociedades que no han tenido relaciones entre sí. Las culturas colocadas en relaciones jerárquicas poseen características inherentes que determinan los límites y direcciones de su creatividad cultural. En esta dirección, la experiencia que ofrece la vivencia cultural misma resulta irrelevante. Lehmann, al igual que como lo hará Asturias posteriormente, refiere a "la fantasía exuberante del hombre primitivo" (1926, p. 409).

Cuadernos de Antropología 2014, 24(2), 3-24 
que había tenido el Instituto Carnegie, tales como el estudio de los hábitos de consumo alimenticio, el análisis de los procesos de mercantilización y la diversidad lingüística. Abigael E. Adams (2008) discute las tesis de Jorge Ramón González-Ponciano para mostrar que Goubaud Carrera se distanció de los influyentes estadounidenses, ofreciendo una visión crítica a las tradicionales jerarquías étnicas. Efectivamente, Redfield y Tax, en los trabajos analizados anteriormente, carecieron de esa sensibilidad hacia la diferencia que caracteriza la obra de Goubaud. Ambos estadounidenses visibilizaron el mundo indígena desde su posición de poder y desde sus propios referentes culturales. La influencia que sobre Goubaud tuvo la visión objetiva y distante de los antropólogos estadounidenses sobre su "objeto" de estudio y su esfuerzo por homogenizar las culturas indígenas devela, tras su mirada amable, una expresa voluntad intelectual por representar tales sociedades de acuerdo con los intereses de una propuesta integradora y modernizadora.

Desde la dirección del Instituto Indigenista, como intelectual orgánico del estado guatemalteco, se aboca no solo a crear estrategias de integración del indígena a la sociedad guatemalteca, sino también a la construcción de una visión del mundo indígena que muestre cuán oportuno y viable resulta este proyecto. Es decir, pretende convencer a una sociedad tradicionalmente racista y segregacionista de que el indígena puede llegar a convertirse en un digno integrante de la nación guatemalteca.

Si bien Goubaud conoce trabajos etnográficos que se han mostrado sensibles a la diversidad cultural del mundo indígena guatemalteco y él mismo, como estudioso de las lenguas de los diversos grupos étnicos ha advertido las distancias culturales existentes entre las poblaciones, en "Algunos aspectos de la estructura del carácter de los indios de Guatemala" nos retrata un mundo indígena sencillamente homogéneo. En el artículo "Del conocimiento del indio guatemalteco" cita ampliamente los trabajos de Lilly de Jongh Osborne (1964a), quien a partir del estudio de los tejidos profundiza en la diversidad de la cultura y en particular de las construcciones genéricas del altiplano guatemalteco, mostrando las profundas desigualdades existentes entre los sexos. No obstante, Goubaud insiste en homogenizar las relaciones familiares idealizando la situación de la mujer en las comunidades indígenas, ya que, en su criterio, "tiene un lugar de mucha igualdad en la vida doméstica en lo que toca a la educación de los hijos y también en materias de tipo económico" (1964b, p. 218). Estas palabras, publicadas por primera vez en 1949, en pleno auge de la revolución guatemalteca, construyen el universo familiar indígena como un espacio amable a los ojos de las mujeres particularmente urbanas que para entonces se integran a la vida cívica guatemalteca (Carrillo, 2004). Posiblemente, su empeño en la homogenización del indígena resida en que la diversidad étnica, ubicada dentro de las lógicas mismas de la integración nacional, resultaba problemática. ¿Cómo asir otredades múltiples para hacerlas operar, sin llegar a su anulación, en una propuesta de construcción identitaria nacional? Validar características de la cultura indígena en el proceso de integración nacional demanda de una especie de selección de elementos culturales que no dejan de ser una construcción desde el mundo hegemónico, de una ideal sociedad indígena ${ }^{30}$.

30 Spurr (1993), refiriéndose a las propuestas discursivas de la izquierda estadounidense durante la guerra de su país contra Vietnam, sostiene que estas construyeron una representación amable de los vietnamitas, acercándolos tanto como fuera posible al "ideal americano", es decir, creándoles una identidad ajustada a los valores de Occidente.

http://revistas.ucr.ac.cr/index.php/antropologia 


\section{Conclusiones}

Estas páginas exploran cómo el deseo por conocer y describir otredades ha generado diversidad de experiencias de (des)encuentro y formas de representación de la pluralidad social. La propuesta analítica ha distado de ser comprensiva de los estudios etnográficos sobre el altiplano guatemalteco que tuvieron lugar durante la primera mitad del siglo XX. Sin embargo, los autores incluidos han mostrado la pluralidad de ópticas ensayadas sobre estos universos de otredad y, especialmente, han visibilizado la diversidad de construcciones subjetivas que acompañan dichas ópticas. Así mismo, se ha mostrado la relación interactiva entre los recursos de aproximación del etnógrafo al objeto-sujeto de estudio y la creación de los sujetos de interés etnográfica. Inevitablemente escribimos desde algún lugar, desde una particular posición teórica y ética y desde nuestra propia subjetividad. Aunque no hay una relación de necesidad entre una mirada externa y una posición jerárquica, que se corresponda con una mirada interna y una posición horizontal, lo cierto es que las distancias no solo pueden ser indicativos de puntos de partida racistas, sino que también tienden a clausurar la mirada del investigador dentro de sus propios referentes. El trabajo de Goubaud Carrera y, en general del Instituto Indigenista, aun cuando está orientado a abrir el horizonte democrático al ofrecer un espacio dignificador a la cultura indígena en el imaginario nacional, no escapa a lógicas constructivas que distancian al etnógrafo de la otredad bajo análisis. En este caso, el proyecto político nacional se impone sobre la construcción del conocimiento. Más allá de conocer las distancias entre la pluralidad indígena y el mundo ladino, el esfuerzo se dirige a construir representaciones de la otredad que armonicen con los referentes propios de la cultura hegemónica. La preminencia de transformar e integrar impone las reglas del juego que guían la creación del conocimiento. Los etnógrafos estadounidenses, al centrar su mirada en el análisis de las expresiones de la cultura valoradas desde sus propios referentes, se sorprenden ante el contraste de ese moderno homoseconomicus con sus oscuros espacios culturales, ininteligibles en mentes diseñadas para operar en el mundo civilizado. Se sienten fascinados y atraídos ante toda manifestación que interpretan como síntoma de modernización y, a la vez, se capta en su retórica malestar frente a esas expresiones "arcaicas" de los mundos indígenas.

En este viaje a través de la etnografía de las primeras décadas del siglo XX, ha resultado particularmente sugerente el trabajo de Schultze-Jena no solo por sus alcances en términos del conocimiento, sino también desde una perspectiva ética. Él intenta conocer a partir de la subjetividad del otro. Mediante el lenguaje, ingresa en la lectura de un universo distinto, pero comprensible, cuya atracción no reside en su exotismo, su anomalía, sino en su diferencia. Se podría decir, siguiendo a Clifford Geertz (1990) que su semiótica de la cultura conduce a una etnografía que "amplía el universo humano... [pero a la vez] logra captar su carácter normal sin reducir su particularidad" (p. 27). Su perspectiva no parte de una propuesta de transformación de la otredad, solo busca aproximarse a su experiencia para captarla en su dimensionalidad. Narrativa que se abre a lo que Homi Bhabha (1990) llama "la perplejidad de la vida". Gracias a ella logramos desprendernos de las certezas para aprehender territorios ignotos de conocimiento a partir de su diferencia.

Cuadernos de Antropología 2014, 24(2), 3-24 


\section{Referencias bibliográficas}

Adams, A. E. (2008). ¿Diversidad cultural en la nacionalidad homogénea? Antonio Goubaud Carrera y la fundación del Instituto Indigenista Nacional de Guatemala. Mesoamérica, 50, 66-95.

Adams, R. (1956). Cultura indígena de Guatemala. Ensayos de Antropología Social. Seminario de integración social de Guatemala, Guatemala: Ministerio de Educación Pública.

Adams, R. (1964). Introducción a la antropología aplicada. Seminario de integración social guatemalteca, Guatemala: Ministerio de Educación Pública.

Adams, R. (1995). Etnias en evolución social. Estudios de Guatemala y Centroamérica. México, D.F.: Universidad Autónoma Metropolitana-Unidad Iztapalapa.

Adams, J. y Bolaños, M. (1996). Aproximación histórica al desarrollo de la antropología norteamericana en Centroamérica. 1930-1990. En C. Murillo (ed.), Antropología e identidades en Centroamérica (pp. 25-41). San José: Oficina de Publicaciones de la Universidad de Costa Rica.

Anónimo. (1859). A Visit to the Guajiquero Indians. En J. C. Vargas (2008; comp.) Tropical travel. The representation of Central America in the $19^{\text {th }}$ century (pp. 235-254). San José: Editorial UCR.

Anónimo. (1946). Trayectoria del Instituto. Boletín del Instituto Indigenista Nacional, 2-3, 3-12.

Bhabha, H. (1990). DissemiNation: time, narrative, and the margins of the modern nation. En H. K. Bhabha (ed.) Nation and narration (p. 313). New York: Routledge.

Blanchette, T. (2010). La antropología aplicada y la administración indígena en los Estados Unidos (19341945). Desacatos, 33, 33-52.

Bolaños, M. (1999). Anthropological approaches in U.S. studies of Central America, 1930-1970 (tesis doctoral inédita). Universidad de Kansas, Kansas.

Bovallius, C. (1997). Estadía en Costa Rica. (julio a octubre de 1882). En E. Zeledón (ed.), Viajes por la República de Costa Rica (pp. 87-159). San José: Editorial de la Dirección de Publicaciones del Museo Nacional de Costa Rica.

Broda, J. (2008). Leonhard Schultze-Jena y sus investigaciones sobre ritualidad en la montaña de Guerrero. American Antropology, 42, 117-145.

Carrillo, L. (2004). Luchas de las guatemaltecas del siglo XX. Mirada al trabajo y la participación política de las mujeres. Guatemala: Ediciones del Pensativo.

Clifford, J. (1995). Dilemas de la cultura. Antropología, literatura y arte en la perspectiva posmoderna. Barcelona: Gedisa Editorial.

Cornejo-Polar, A. (1994). Escribir en el aire. Ensayo sobre la heterogeneidad socio-cultural en las literaturas andinas. Lima: Editorial Horizonte.

De León, C. (1950). Guía turística de Guatemala. Guatemala: Editorial del Ministerio de Educación Pública.

De León, C. H. (1996). Somos arqueólogos... somos investigadores: La arqueología tradicional, lo maya, lo indio y la nación. Una visión más amplia de la terminología antropológica. Estudios, 3, 7-16.

Diesseldorff, E. P. (1926). Conferencia de Erwin. P. Diesseldorff. Anales de la Sociedad de Geografía e Historia, 2, 378-386.

http://revistas.ucr.ac.cr/index.php/antropologia 
Dogan, M. y Pahre, R. (1990). Las nuevas ciencias sociales. La marginalidad creadora. México D.F.: Editorial Grijalbo.

Geertz, C. (1988). El antropólogo como autor. Barcelona: Editorial Paidós.

Geertz, C. (1990). La interpretación de las culturas. España: Editorial Gedisa.

González-Ponciano, J. R. (1989). Guatemala, el Estado y los indígenas. Estudios. Revista de Antropología, Arqueología e Historia, Tercera Época, 35-48.

González-Ponciano, J. R. (1997). Guatemala, la nación y las comunidades. Culturas de Guatemala, s.n., 297-321.

Goubaud, A. (1946). El grupo étnico indígena. Criterios para su definición. Boletín del Instituto Indigenista Nacional, 2(2-3), 13-30.

Goubaud, A. (1964a). Del conocimiento del indio guatemalteco. En A. Goubaud, Indigenismo en Guatemala (pp. 109-139). Guatemala: Ministerio de Educación Pública.

Goubaud, A. (1964b). Algunos aspectos de la estructura del carácter de los indios de Guatemala. En A. Goubaud, Indigenismo en Guatemala (pp. 207-227). Guatemala: Ministerio de Educación Pública.

Goubaud, A. (1968). Prefacio. En O. Stoll, Etnografia de Guatemala (XV-XLVI.). Guatemala: Editorial del Ministerio de Educación Pública.

Haberland, W. (1995). Recuerdos de un maestro: Karl Ferdinand Franz Termer (1894-1968). Mesoamérica, 30, 371-388.

Hendrickson, C. (1997). Imágenes del maya en Guatemala. El papel del traje indígena en las construcciones del indígena y del ladino. Mesoamérica, 33, 15-40.

Huxley, A. (1960). Beyond the Mexican Bay. New York: Vintage Books.

Kramer, W., Lovell, G. y Lutz, C. H. (1994). La conquista española de Centroamérica. En J. Pinto (ed.), Historia general de Centroamérica. El régimen colonial (pp. 21-93). Tomo II. San José, Costa Rica: FLACSO.

Kutscher, G. (1976). Berlín como centro de estudios americanistas. Ensayo bio-bibliográfico. Indiana, 7 , $1-73$.

Lehmann, W. (2001). Walter Lehmann. En M. A. Quesada (comp.), Entre silladas y rejoyas. Viajeros por Costa Rica de 1850 a 1950 (pp. 475-570). Cartago: Editorial Tecnológica de Costa Rica.

Lehmann-Nitsche, R. (1926). Mitología centroamericana por el doctor R. Lehmann-Nitsche, profesor del Museo de la Plata, Argentina. Anales de la Sociedad de Geografia e Historia, II, 408-414.

León, J. (1938). Exposición de telas indígenas guatemaltecas en el Museo Etnográfico de Hamburgo en diciembre de 1937 por la socia Elly von Khulmann, Wesibaden, Alemania. Anales de la Sociedad de Geografia e Historia, año XIV, tomo XIV, 4, 432-438.

Lewiw, H. S. (2001). The passion of Franz Boas. American Anthropologist, 2(103), 447-467.

López, E. S. (1995). La arqueología tradicional. Lo maya, el problema del indio y la nación. Estudios. Revista de Antropología, Arqueología e Historia, 2, 63-77.

Mosk, S. (1956). Economía indígena en América Latina. En R. Adams (ed.), Cultura indígena de Guatemala. Ensayos de Antropología Social. Seminario de integración social de Guatemala, Guatemala: Ministerio de Educación Pública. 
Palma, G. (1995). Las preocupaciones historiográficas de la Sociedad de Geografía e Historia de Guatemala. Estudios. Órgano de difusión del Instituto de Investigaciones Históricas, Antropológicas y Arqueológicas, 95(1), 67-84.

Pratt, M. L. (2003). Imperial eyes. Travel writing and transculturation. Londres: Routledge.

Redfield, R. (1956a). Comerciantes primitivos de Guatemala. En R. Adams (ed.), Cultura indigena de Guatemala. Ensayos de Antropología Social (pp. 43-59). Seminario de integración social de Guatemala, Guatemala: Ministerio de Educación Pública.

Redfield, R. (1956b). La cultura y la educación en el Altiplano Medio-Occidental de Guatemala. En R. Adams (ed.), Cultura indígena de Guatemala. Ensayos de Antropología Social (pp. 213-231). Seminario de integración social de Guatemala, Guatemala: Ministerio de Educación Pública.

Rodríguez, O. (1989). La teoría del subdesarrollo de la CEPAL. México: Siglo XXI.

Sapper, K. (1930). La América Central. Anales de la Sociedad de Geografia e Historia, año V, tomo VI, 4, 446-453.

Schultze-Jena, L. (1954). La vida y las creencias de los indígenas quichés de Guatemala (2 ${ }^{\text {da }}$ ed.). Guatemala: Biblioteca de Cultura Popular.

Spurr, D. (1993). The rhetoric of empire. Colonial discourse in journalism, travel writing and imperial administration. Durham y Londres: Duke University Press.

Stephens, J. L. (1982). Incidentes de viaje en Centroamérica y Chiapas y Yucatán (Tomo I). San José: Educa.

Stoll, O. (1968). Etnografía de Guatemala. Guatemala: Editorial del Ministerio de Educación Pública.

Taracena, A. y Gellert, G. (2002). Etnicidad, estado y nación en Guatemala, 1808-1944 (Vol. 1). Antigua Guatemala: Cirma.

Tax, S. (1945-1947). La economía regional de los indígenas de Guatemala. Boletín del Instituto Indigenista Nacional, I-II, 75-87.

Tax, S. (1956). La visión del mundo y las relaciones sociales en Guatemala. En R. Adams (ed.), Cultura indígena de Guatemala. Ensayos de Antropología Social (pp. 95-121). Seminario de integración social de Guatemala, Guatemala: Ministerio de Educación Pública.

Tenorio, M. (1998). Artilugio de la nación moderna. México en las exposiciones universales. 1880-1930. México, D.F.: Fondo de Cultura Económica.

Termer, F. (1957). Etnología y etnografía de Guatemala. Guatemala: Ministerio de Educación Pública.

Vela, D. (1946). Importancia de la antropología aplicada. Boletín del Instituto Indigenista Nacional, I-II, 66-69.

Wagner, R. (1996). Los alemanes en Guatemala. 1828-1944. Guatemala: Afanes, S.A.

Weber, M. (2006). Ética protestante y el espíritu del capitalismo. México, D.F.: Editorial Éxodo.

Zimmerman, A. (2001). Anthropology and antihumanism in imperial Germany. Chicago, EE. UU.: The University of Chicago Press. 